\title{
Nueva Sección: Rescate
}

A partir de este número del Journal de Ciencias Sociales de la Universidad de Palermo, incorporamos esta sección, cuyo sentido es recuperar textos científicos o ensayísticos no recientes pero todavía actuales cuyo eje estructural sea la interdisciplinariedad. En efecto, los trabajos interdisciplinarios adquieren hoy día una importancia decisiva, ya que resulta cada vez más imprescindible para los investigadores la integración de disciplinas diversas para constituir su objeto de estudio y su marco teórico. Desde esta perspectiva, buscamos recuperar textos pioneros en esta metodología.

Susan Buck-Morss (2005): Hegel y Haití. La dialéctica amo-esclavo: una interpretación revolucionaria. Buenos Aires: Norma/Colección Vitral. 104 páginas. ISBN: 987-545-210-6. Traducción de Fermín Rodríguez.

Daniel Del Percio

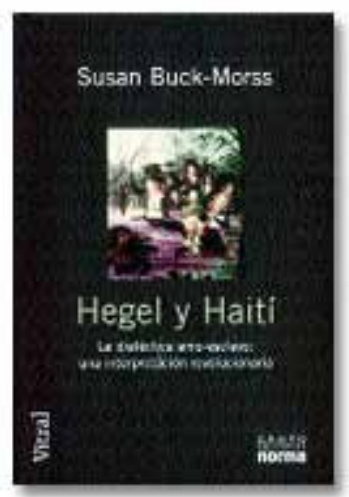

Material original autorizado para su primera publicación en el Journal de Ciencias Sociales, Revista Académica de la Facultad de Ciencias Sociales de la Universidad de Palermo.

Recibido: 15-3-2015

Aprobado: 15-4-2015

La lectura del breve pero sólido libro de Susan Buck-Morss Hegel y Haití constituye una invitación a repensar los fructíferos pero a veces esquivos vasos comunicantes que unen la Historia con la Filosofía, el Periodismo, y las Ciencias Políticas². Organizado en doce breves capítulos, el texto de la doctora Buck-Morss manifiesta la necesidad de los estudios interdisciplinarios para evitar lecturas sesgadas de la Historia. En efecto, el primer capítulo plantea fuertemente las dos líneas, temática

${ }^{1}$ Doctor en Letras. Magíster en Diversidad Cultural. Docente e Investigador del CICS, Universidad de Palermo.

${ }^{2}$ La primera edición en inglés es del año 2000, Hegel and Haití. 
una y metodológica la otra, que lo justifican: el origen de la dialéctica amo-siervo por un lado, la crítica a la investigación histórica y filosófica tradicional por el otro.

En efecto, desde el segundo capítulo la autora norteamericana describe el entretejido que une a la Historia y la Historia de las ideas políticas, particularmente las vinculadas con la así llamada "diáspora africana". En efecto, el tráfico de esclavos desde África hacia América para ser utilizados en las plantaciones fue vital en el desarrollo del capitalismo, pero pronto generó profundas contradicciones con las concepciones republicanas, que resultaron manifiestas en John Locke y Thomas Hobbes, quienes tenían importantes intereses económicos vinculados directa o indirectamente con la trata de esclavos (la autora hace un minucioso análisis de ellas). La esclavitud constituirá durante casi dos siglos (de hecho, hasta la Revolución Haitiana) prácticamente la base de la economía europea de aquel entonces, hecho que Buck-Morss ejemplifica claramente, al señalar que uno de cada cuatro adinerados franceses de mediados del siglo XVIII había amasado su fortuna gracias al trabajo esclavo en las plantaciones americanas.

En el capítulo quinto, la autora profundiza el estudio de estas contradicciones, de las que el propio Jean-Jacques Rousseau no puede escapar. Éstas precisamente adquieren su punto más alto cuando en 1794, inmersos en el clima de la reciente Revolución Francesa, los comisionados coloniales franceses de Santo Domingo (la actual Haití) Sonthonax y Polverel, actuando por cuenta propia declaran la abolición de la esclavitud y del Code Noir en todas las colonias francesas ${ }^{3}$. Luego, después de que el ejército negro de Toussaint-Louverture derrotó incluso a Inglaterra (que también sufrirá una serie de desastres militares en las así llamadas "Guerras Cimarronas" contra los esclavos fugitivos de la isla de Jamaica), surgirá la primera constitución haitiana, redactada por el propio Toussaint-Louverture, ex esclavo devenido gobernador de la isla ${ }^{4}$. Su aporte, más allá del fuerte personalismo que el líder de la revolución impuso a la Carta Magna, será precisamente la abolición de la esclavitud. Será la primera constitución del mundo en hacerlo, como fue también ella producto de la primera revolución de esclavos que resultó triunfante.

Todos estos conflictos convergen en el capítulo sexto, en donde la autora sintetiza la importancia de la revolución haitiana de manera altamente significativa, remarcando su diferencia con lo sucedido en la América del Norte, en donde se debió esperar a la Guerra de Secesión para ver el fin legal de la esclavitud: "La Revolución haitiana fue el téster, la prueba de fuego para los ideales del lluminismo

\footnotetext{
${ }^{3}$ El Code Noire es la ley que regulaba el comercio de esclavos dentro de Francia y sus colonias.

${ }^{4}$ El poeta inglés William Wordsworth escribió un soneto en homenaje a Toussaint-Louverture, publicado luego por la revista alemana Minerva, a la que Hegel estaba suscripto. Originalmente, el soneto había sido publicado por el diario inglés Morning Post el 2 de febrero de 1803. Minerva solía publicar traducciones de artículos de los periódicos ingleses.
} 
francés. Y todo europeo que fue parte del público lector burgués lo sabía" (p.44). En efecto, todo europeo burgués y lector estaba al tanto de lo que sucedía en Santo Domingo, y el medio por el cual obtenía la información era esencialmente el periodismo, a partir de distintas publicaciones inglesas, francesas, norteamericanas y, en el caso particular de Alemania, de la revista Minerva, editada por el pensador (y miembro de la masonería) Johann Wilhelm von Archenholz. Apenas dos años después de haber sido fundada, en 1794, Minerva tenía la reputación de ser el mejor periódico político europeo, y en 1798 alcanzaba una edición de 3000 ejemplares por número, una tirada absolutamente respetable incluso para una revista política actual. Entre sus lectores podemos encontrar al Kaiser Federico Guillermo III de Prusia, a los escritores Goethe y Schiller (este último fue amigo personal de Archenholz), el poeta Klopstock, el filósofo Schelling y Lafayette. Y, por sobre todo, el mismo Georg Wilhelm Friedrich Hegel.

Los hábitos de lectura de Hegel, que incluían una manifiesta curiosidad por los periódicos como rutina matinal, aparecen como un elemento más a tener en cuenta en la formulación de la pregunta por el surgimiento de la idea de la dialéctica amo-siervo. La autora en el capítulo 7 analiza precisamente los problemas que generó el intento de responder a esta cuestión si se ignoraban las lecturas de las noticias de la época. La redacción de la Fenomenología del espíritu, que abarcó los años 1805-1806 aparece solapada un año con el ciclo de las notas que Minerva publicó sobre la revolución haitiana: 1804-1805. En la breve historia que desarrolla la autora sobre las teorías acerca del origen de esta dialéctica, se hace evidente la ignorancia que los estudiosos de la obra de Hegel tenían de esta inesperada vinculación con el periodismo, desconocimiento que Susan Buck-Morss atribuye a los estudios disciplinarios, que impedían una apertura hacia otras vertientes de análisis y de método. Precisamente por esto, luego de hacer una síntesis de la dialéctica amo-siervo en el capítulo octavo, desarrolla en el noveno un estudio riguroso sobre la omisión de Haití en casi todos los análisis previos, limitados a una metodología dentro de los límites disciplinarios de la filosofía, y de la historia de la filosofía en particular, al punto de centrar la responsabilidad de este olvido en la "apropiación marxista de una interpretación social de la dialéctica hegeliana" (p. 71), que cerró las fronteras de otros análisis posibles, en particular a partir de Luckács y Marcuse. Porque, como sintetiza magistralmente la autora en la página 77:

Teoría y realidad convergen en ese momento histórico. O bien, para decirlo en un lenguaje hegeliano, lo racional -la libertad- se volvió real. Éste es el punto crucial para entender la originalidad del 
argumento de Hegel, por el cual la filosofía desborda los confines de la teoría académica y se vuelve un comentario sobre la historia.

Este "más allá de las teorías académicas", cuando el pensamiento se transforma en una visión concreta de la Historia, hace evidente la carnalidad que subyace detrás de toda idea, y manifiesta el vínculo absolutamente material y vivencial en el que se soportan las teorías que aspiran a una larga vida. En efecto, estas ideas (criticadas, menospreciadas, admiradas y transformadas) tienen un "más allá" de su propia disciplina, al estar unida por, muchas veces, invisibles vasos comunicantes con la vida y su dinámica. No es posible, entonces, pensar la filosofía sin la historia y sin la crónica propia de la época. Una interdisciplinariedad puede reconstituir esos nexos que la propia dinámica de las disciplinas no pocas veces invisibilizan.

El capítulo décimo, acaso un tanto anómalo a primera vista, muestra los vínculos entre la masonería y la Revolución Haitiana, incluso en sus facetas más extrañas y esotéricas como la religión vudú. En efecto, como han mostrado cada uno a su manera el sociólogo haitiano Laennec Hurbon y el novelista cubano Alejo Carpentier, el esoterismo y la magia fueron formas de resistencia y de identidad cultural afroamericana ${ }^{5}$. Pero aun así, quizás este apartado no tendría mucha relación con el resto del libro si no fuera por el capítulo 11, en donde la autora traza, sin atenuantes, una descripción de la posición de Hegel sobre la esclavitud, casi de aprobación por parte del filósofo alemán o, al menos, de justificación cultural. Lo "salvaje" no podía ser "libre" sin una previa evolución. Por tanto, lo salvaje, lo bárbaro (para usar un concepto que atraviesa nuestra cultura en su dicotomía con la civilización) según Hegel debe ser necesariamente esclavo hasta el momento de su madurez para alcanzar la libertad. Acaso esta idea también haya surgido de las terribles noticias que llegaban de la isla de Santo Domingo: el país liberado por los esclavos, los esclavos liberados por sí mismos (por primera y única vez en la historia) sucumbieron a sí mismos, y Haití adquirió la fisonomía de un imperio, grotesco, cruel y maravilloso a la vez, dirigido por un ex-esclavo, Henri Christophe que se autodenominó emperador y copió punto por punto a la corte francesa. El siervo se volvió un amo “igual” al anterior. Carpentier lo mostrará con toda su crudeza y sus contradicciones en la tercera parte de su novela El reino de este mundo. La historia contemporánea de Haití, tan trágica, es tributaria de este pasado.

Finalmente, en el último capítulo la doctora Susan Buck-Morss hace el balance de la importancia de

${ }^{5}$ De Hurbon podemos mencionar sus libros Dios y el Vudú haitiano y El bárbaro imaginario. De Carpentier, su novela histórica El reino de este mundo, en donde realiza una singular unión de lo maravilloso del mundo afroamericano con la dialéctica hegeliana del amo y el siervo. 
indagar en este "silencio" sobre el rol de las noticias de la revolución haitiana en Hegel. Un silencio "racista" a pesar de él, porque hace invisible la carnadura de la historia detrás de un método. Una historia "in-disciplinada" sería la propuesta necesaria que la autora hace para recuperar lo invisible, lo acallado. Como algunas veces sucede, la indisciplina es creadora, porque rompe con una tradición equivocada. Así sucedió con los esclavos que se rebelaron: como ejército sin bandera, al enfrentarse a los franceses ejercieron un derecho que fue, a la vez, un acto de ruptura fundacional: tomaron una bandera francesa, y le arrancaron la franja blanca, como signo de no pertenecer ya a la raza opresora. Esta insignia desgarrada es la síntesis de una Historia que no merece el silencio. 